\title{
Astroglial cells in primary culture: A valid model to study Neospora caninum infection in the CNS
}

\author{
A.M. Pinheiro ${ }^{\text {acc, } *}$, S.L. Costa ${ }^{a}$, S.M. Freire ${ }^{b}$, M.A.O. Almeida ${ }^{c}$, \\ M. Tardy ${ }^{\mathrm{d}}$, R. El Bachá ${ }^{\mathrm{a}}$, M.F.D. Costa ${ }^{\mathrm{a}}$

 \\ ${ }^{\mathrm{b}}$ Laboratório de Imunologia e Biologia Molecular, Instituto de Ciências da Saúde, Universidade Federal da Bahia, Brazil \\ ${ }^{c}$ Laboratório de Doenças Parasitarias dos Animais, Escola de Medicina Veterinária, Universidade Federal da Bahia, Brazil \\ ${ }^{\mathrm{d}}$ Laboratory of "Cell plasticity and Therapy" Inserm (U-421) and UPVM Paris XII, France
}

Received 9 November 2005; accepted 3 May 2006

\begin{abstract}
The protozoan Neospora caninum has a veterinary importance because it causes abortion in cattle and neuromuscular alterations in dogs. We infected rat astrocytes, in vitro, with different concentrations of $N$. caninum. Astrocytes responded to infection by producing the pro-inflammatory cytokine TNF- $\alpha$ and the neurotoxic-free radical NO, 24 and $72 \mathrm{~h}$ post-infection. These data suggest that astrocytes, which are essential for brain function, are targets for the parasite and this represents a practical and valid model to study the effects of $N$. caninum on the CNS.
\end{abstract}

(C) 2006 Elsevier B.V. All rights reserved.

Keywords: Neospora caninum; Astrocytes; Model; Infection; TNF- $\alpha$ and NO

\section{Introduction}

Neospora caninum is a protozoa of the phylum Apicomplexa that is responsible for abortion in cattle and neuromuscular disorders in dogs. This is an important parasite distributed worldwide and many studies have been conducted about neosporosis (Dubey, 1999, 2003). N. caninum has satisfactory growth and development in different kinds of cell

\footnotetext{
* Corresponding author. Tel.: +55 $7132406031 / 99831768$.

E-mail address: amp1@uol.com.br (A.M. Pinheiro).
}

cultures, including primary cultures of bovine fetal brain which contain mainly neurons together with $10-15 \%$ of astroglia and about $20 \%$ un-identified cells (Yamane et al., 2000). Astrocytes represent one of the most important cell types in the mammalian CNS. These cells are involved in each stage of the brain development, in brain homeostasis control, in the synapse function, in the brain immune response and in most brain pathologies (for a review see Tardy, 1991; Norenberg, 1994; Pekny and Nilsson, 2005). We therefore propose rat brain astroglial primary cultures as an easy, practical and cheap in vitro 
model, to study the effects of a parasite infection in the CNS.

\section{Material and methods}

\subsection{Astroglial primary cultures}

Astrocytes were obtained from the cortex of newborn rats $(<48 \mathrm{~h})$ and mechanically dissociated through an $80 \mu \mathrm{m}$ filter and $10^{6}$ cells were seeded onto culture dishes of $40 \mathrm{~mm}$ in diameter (TPP, Switzerland). The cultures were maintained in DMEM (Dulbecco's modified Eagle's medium, CULTILAB, Brazil) supplemented with $10 \%(\mathrm{v} / \mathrm{v})$ fetal bovine serum (CULTILAB), $1 \mathrm{mM}$ pyruvic acid (Sigma) and $2 \mathrm{mM}$ glutamine (Sigma). Cultures were incubated at $37{ }^{\circ} \mathrm{C}$ in a humidified atmosphere of $5 \%$ $\mathrm{CO}_{2}$ and the culture medium was changed three times a week (Costa et al., 2002). After 2-3 weeks of culture, cells covered all the surface of dishes and were considered confluent. At this time, cells were examined and counted by immunofluorescence microscopy using antibodies raised against glial fibrillary acidic protein (GFAP), a specific astroglial marker (described below). Each culture monolayer contained about $95 \%$ GFAP expressing cells. A group of astrocytes was infected after they became confluent $(n=12)$ and cultured in parallel with non-infected controls $(n=12)$. Three independent experiments were performed. Three plates from each group were used in each independent experiment for immunocytochemistry $6,24,48$ and $72 \mathrm{~h}$ after infection. Cell culture medium was obtained 24 and $72 \mathrm{~h}$ post-infection and used for the assay of $\mathrm{TNF}-\alpha$ and nitrite.

\subsection{N. caninum culture}

Tachyzoites of the NC-Bahia strain (Gondim et al., 2001) were maintained in Vero cells, with regular changes of the DMEM medium (supplemented with $10 \%$ fetal bovine serum) every $48 \mathrm{~h}$.

\subsection{Infection of astroglial cultures}

Tachyzoites were purified by exclusion chromatography on a Sephadex G25 column. The parasites were counted and cell:tachizoite ratios of $0,5: 1,1: 1$ and $2: 1$ were tested for $6,24,48$ and $72 \mathrm{~h}$ after infection.

\subsection{Immunocytochemistry}

Cells were treated with ice-cold methanol for $20 \mathrm{~min}$ and blocked with $3 \%$ of BSA for $1 \mathrm{~h}$ at room temperature. They were stained with rabbit anti-GFAP IgG antibody (DAKO, Denmark) diluted 1:500 in PBS, and then incubated with tetramethyl-rhodamine isothiocyanate (TRITC) conjugated anti-IgG (Cappel, Durham, Canada) at 1:500. Nuclear dye Hoechst 33258 was used for detection of DNA fragmentation. Serum from a dog experimentally infected with $N$. caninum was diluted 1:50 (Pinheiro et al., 2005) and FITC-conjugated anti-dog IgG (BETHYL, USA) at 1:180 was added to detect the infection with the parasite. Normal dog serum and normal rabbit serum were used as negative controls.

\section{5. $T N F-\alpha$}

This cytokine was measured in the supernatant of control and infected cultures by using a commercial kit (Sandwich ELISA, Amershan, UK), according to manufacturer instructions.

\subsection{NO evaluation}

The amount of nitrite $\left(\mathrm{NO}_{2}{ }^{-}\right)$formed in the cell culture supernatant was used as a marker for $\mathrm{NO}$ production according to Griess (Won et al., 2004). Briefly, duplicate aliquots of culture medium $(50 \mu \mathrm{L})$ were mixed with an equal volume of a $1: 1(\mathrm{v} / \mathrm{v})$ mixture of $1 \%$ sulfanilamide in $5 \%$ phosphoric acid and $0.1 \% \mathrm{~N}$-(1-naphthyl) ethylenediamine. Absorbance was read at $490 \mathrm{~nm}$ using an Elx 800 Universal microplate reader (Biotek instruments, Inc., USA). Quantitative standards were generated by serial diluting sodium nitrite into culture medium.

\subsection{Statistical analysis}

The results were expressed as mean \pm S.D. and the comparisons between two groups were done using Student's $t$-test. 

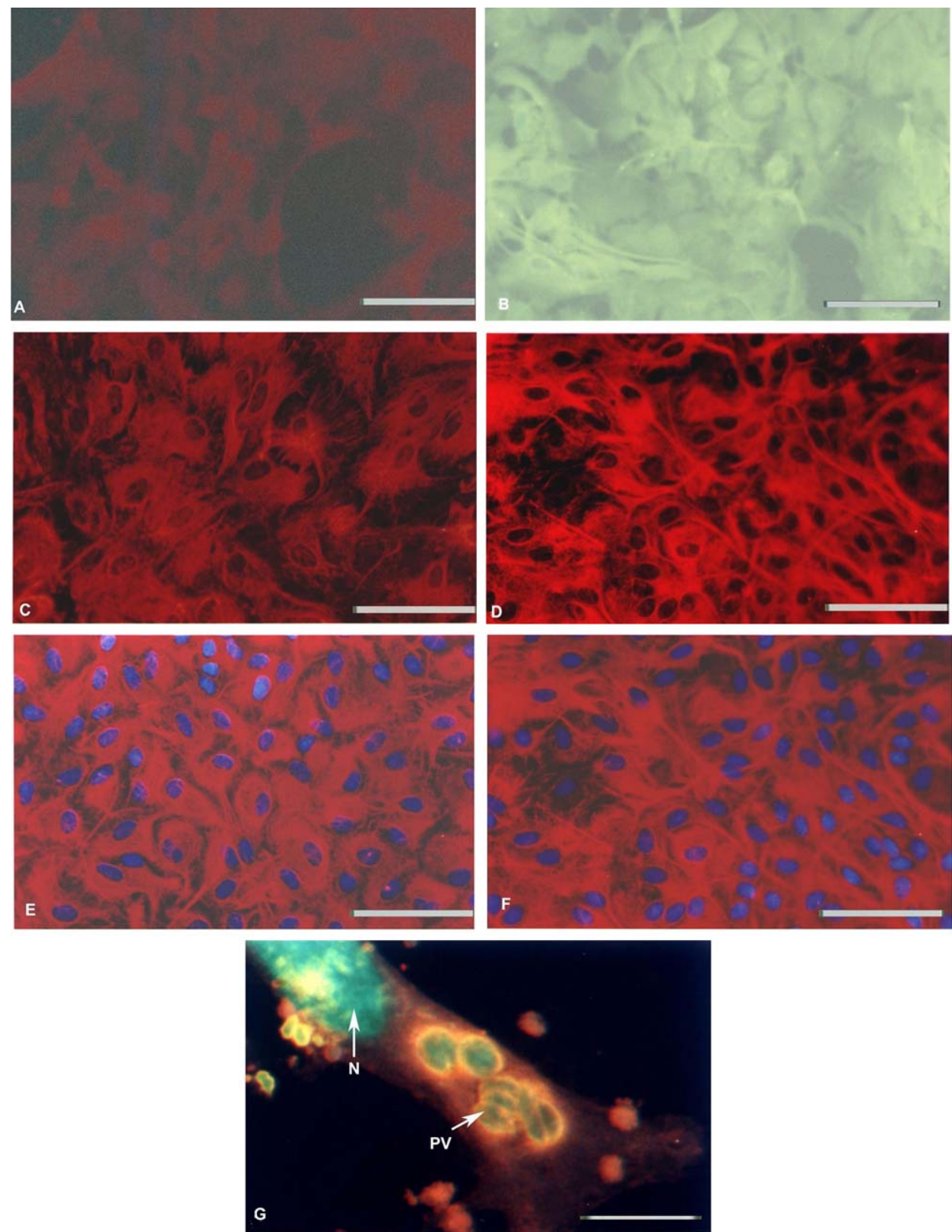

Fig. 1. Immunocytochemistry of non-infected astrocytes and infected astrocytes with Neospora caninum. (A) Non-infected astrocytes were incubated with normal rabbit serum, and then incubated with TRITC conjugated anti-IgG. (B) Infected astrocytes with Neospora caninum were incubated with non-infected dog serum, and then incubated with FITC conjugated anti-IgG. (C) Non-infected astrocytes incubated with rabbit anti-GFAP IgG antibody, and then stained with TRITC conjugated anti-IgG. (D) Infected astrocytes incubated with rabbit anti-GFAP antibody, and then stained with TRITC conjugated anti-IgG. Cell nuclei stained with Hoechst 33258 in non-infected (E) and infected cells cultures (F) shows a regular nuclear morphology. (G) Infected astrocytes incubated with $N$. caninum positive dog serum, and then stained with FITC conjugated anti-IgG. PV, parasitophorous vacuoles; N, nuclei. Bars: A-F, $50 \mu \mathrm{m} ; \mathrm{G}, 10 \mu \mathrm{m}$. 


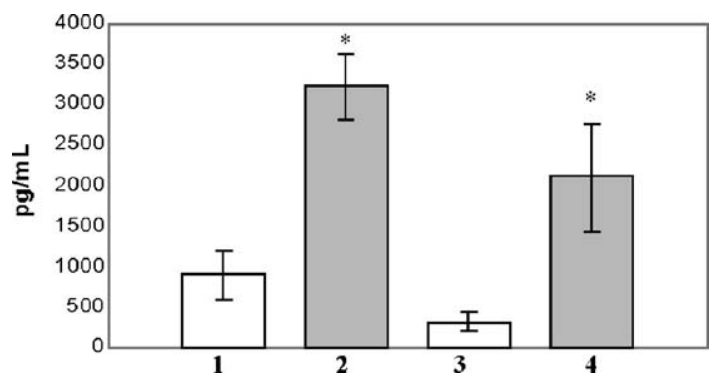

Fig. 2. Evaluation of TNF- $\alpha$ level, $24 \mathrm{~h}$ (2) and $72 \mathrm{~h}$ (4) postinfection and in the control conditions (1 and 3). Results are expressed as mean \pm S.D. " “*” represent a significant difference between infected and control culture $(p<0.001)$.

\section{Results and discussion}

We have shown that cultured astrocytes are targets for $N$. caninum and astrocytes respond to the infection with a high reactivity, illustrated by the gliofilament reorganization in the first $24 \mathrm{~h}$ of infection (Fig. 1CF). The presence of parasites inside the cells was confirmed by immunocytochemistry (Fig. 1G), and no cross reactivity was observed (Fig. 1A and B). The best effector/target ratio for the parasite was 1:1, with good astrocyte viability in the monolayer allowing visualization of parasites in parasitophorous vacuoles inside the infected cells. Using immunocytochemistry there was no visible difference in the parasites number, on the cell monolayer, at 48 and $72 \mathrm{~h}$ post-infection.

$N$. caninum infected astrocytes released TNF- $\alpha$ into the culture medium $24 \mathrm{~h}$ post-infection, suggesting a high pro-inflammatory response of infected cells to the parasite (Fig. 2). The nitric oxide (NO) level in

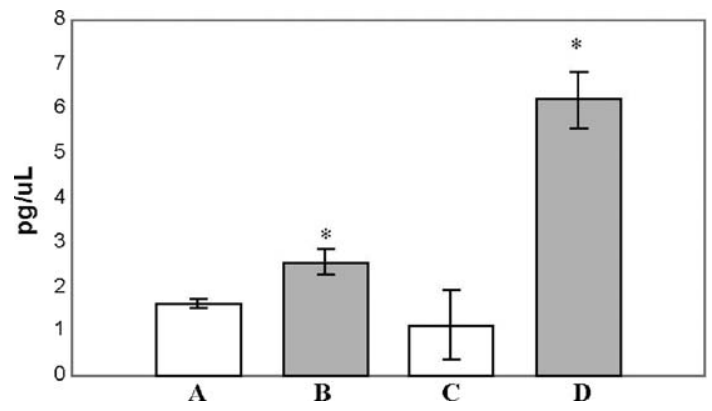

Fig. 3. Production of NO in astrocytes at $24 \mathrm{~h}$ (B) and $72 \mathrm{~h}$ (D) postinfection and in their controls (A: $24 \mathrm{~h}$ and $\mathrm{C}: 72 \mathrm{~h}$ ). Results are expressed as mean \pm S.D. "** represent a significant difference between infected and control culture $(p<0.001)$. the medium also increased at $24 \mathrm{~h}$ post-infection and continued to increase during the course of the infection (Fig. 3), illustrating another potential proinflammatory effect and oxidative events in the infected cells (Gibson et al., 2005). NO is a physiological messenger in the CNS and a marker for oxidative stress. NO can be toxic to neurons and may contribute to the neurodegenerative process associated with gliosis. Its implication in other important functions has been recently reported (Moro et al., 2005). In conclusion, primary cultures of the rat brain cortex predominantly contain astrocytes and these cells are susceptible to $N$. caninum infection. Infected cells have the capacity to release highly proinflammatory and toxic agents in the cell culture environment suggesting that this represents a valid in vitro model to analyze the effects of $N$. caninum infection on the CNS.

\section{Acknowledgments}

Grant supported partially by Conselho Nacional de Desenvolvimento Científico e Tecnológico (CNPq) and Programa de Pós Graduação em Imunologia ICS/ UFBA.

\section{References}

Costa, S., Planchenault, T., Charriere-Bertrand, C., Mouchel, Y., Fages, C., Juliano, S., Lefrancois, T., Barlovatz-Meimon, G., Tardy, M., 2002. Astroglial permissivity for neuritic outgrowth in neuron-astrocyte cocultures depends on regulation of laminin bioavailability. Glia 37, 105-113.

Dubey, J.P., 1999. Neosporosis-the first decade of research. Int. J. Parasitol. 29, 1485-1488.

Dubey, J.P., 2003. Review of Neospora caninum and neosporosis in animals. Korean J. Parasitol. 41, 1-16.

Gibson, C.L., Coughlan, T.C., Murphy, S.P., 2005. Glial nitric oxide and ischemia. Glia 50, 417-426.

Gondim, L.F., Pinheiro, A.M., Santos, P.O., Jesus, E.E., Ribeiro, M.B., Fernandes, H.S., Almeida, M.A., Freire, S.M., Meyer, R., McAllister, M.M., 2001. Isolation of Neospora caninum from the brain of a naturally infected dog, and production of encysted bradyzoites in gerbils. Vet. Parasitol. 101, 1-7.

Moro, M.A., Almeida, A., Bolanos, J.P., Lizasoain, I., 2005. Mitochondrial respiratory chain and free radical generation in stroke. Free Radic. Biol. Med. 39, 1291-1304.

Norenberg, M.D., 1994. Astrocyte responses to CNS injury. J. Neuropathol. Exp. Neurol. 53, 213-220. 
Pekny, M., Nilsson, M., 2005. Astrocyte activation and reactive gliosis. Glia 50, 427-434.

Pinheiro, A.M., Costa, M.F., Paule, B., Vale, V., Ribeiro, M., Nascimento, I., Schaer, R.E., Almeida, M.A., Meyer, R., Freire, S.M., 2005. Serologic immunoreactivity to Neospora caninum antigens in dogs determined by indirect immunofluorescence, western blotting and dot-ELISA. Vet. Parasitol. 130, 73-79.

Tardy, M., 1991. Astrocyte et homéostasie. Médicine/Sciences 7, 799-804.
Won, J.S., Im, Y.B., Singh, A.K., Singh, I., 2004. Dual role of cAMP in iNOS expression in glial cells and macrophages is mediated by differential regulation of p38-MAPK/ATF-2 activation and iNOS stability. Free Radic. Biol. Med. 37, 1834-1844.

Yamane, I., Kitani, H., Kokuho, T., Shibahara, T., Haritani, M., Hamaoka, T., Shimizu, S., Koiwai, M., Shimura, K., Yokomizo, Y., 2000. The inhibitory effect of interferon gamma and tumor necrosis factor alpha on intracellular multiplication of Neospora caninum in primary bovine brain cells. J. Vet. Med. Sci. 62, 347-351. 